\title{
Study on the way of Low Carbon of the Manufacturing Logistics System Xiaobing Pei, Dingfang Jia
}

Tianjin University of Technology, Tianjin 300000, China

Keywords: manufacturing; logistics system; low-carbon economy; environmental pollution

\begin{abstract}
Currently, the development of economic globalization faster, which brings not only just opportunities, more challenges. With the deepening of the global carbon consciousness, China, as the biggest developing country, should follow the world trend, and adhere to the road of sustainable development combined with China's national conditions. Competition among enterprises is not just competing interests and talent competition. Companies should also consider how much pollution to society and how to create value for society. Particularly, the pillar industry of China's first industry is manufacturing industry --- as an important target of energy saving in low-carbon economy and to support the low-carbon production and consumption. In terms of transportation, warehousing, packaging, logistics and information management technologies, manufacturing industry have different levels of resource consumption and energy waste. For such problems, this paper presents the new ideas of developing low-carbon manufacturing logistics system----enhancing the lowcarbon construction of transportation and warehousing, sharing resource, logistics system logistics management and recycling organization. From system level mechanisms, the efficiency of manufacturing logistics systems improved, and logistics costs of manufacturing enterprises reduced. The consumption of resources will be reduced, pollution from the source to the environment will be reduced, and sustainable development will be achieved.
\end{abstract}

\section{Introduction}

Manufacturing logistics is an important part of producer services. It is the key to improve the core competitiveness of the manufacturing and the demand for basic logistics industry.

In China, time is generally less than $10 \%$ from raw materials to finished goods, while more than $90 \%$ of the time in storage, transportation, handling, packaging, distribution and other logistics sectors [1]. In 2012, manufacturing logistics continued rapidly growth, and growth will tend to be more stable. Therefore, it is necessary to study and optimize logistics system of manufacturing enterprise. This paper is to study and optimize the manufacturing logistics systems from view of all aspects of low-carbon.

The main framework of this article is shown in Fig. 1.

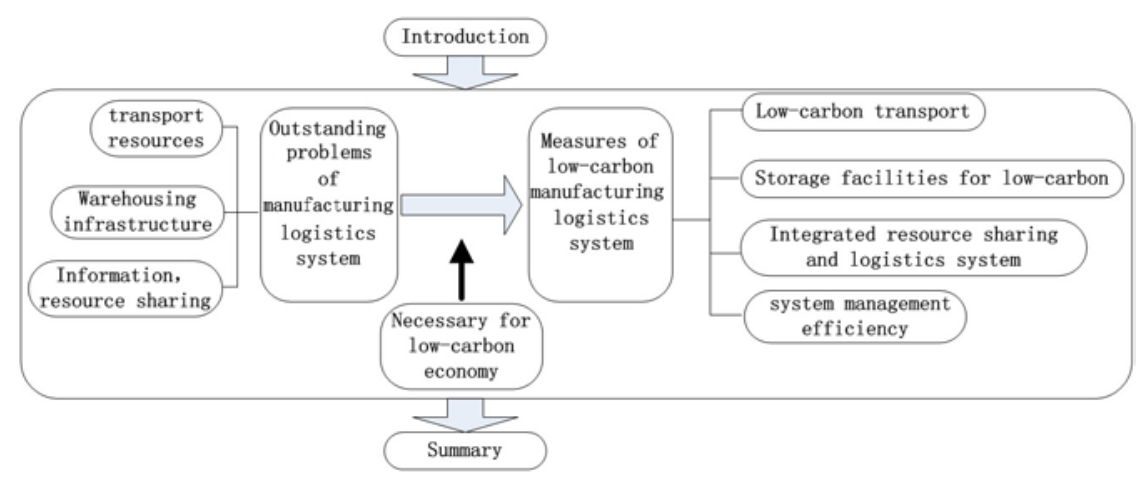

Fig. 1 The main framework

\section{Necessary for low-carbon economy}

Development of low-carbon economy is not only a responsibility of positive commitment to environment. And it is an adjustment of economic structure and an improvement of energy 
efficiency, development of newly industries. It is the need of the construction of ecological civilization. Development model of low-carbon economy is integrated innovation and practice of building a conservation-oriented society. And it is the inevitable choice of China's sustainable development.

Manufacturing logistics is an important target of energy saving in low-carbon economy. In 2002, the whole world Carbon dioxide emissions, transportation accounted for $14 \%$. It shows manufacturing logistics occupies a special position in the low-carbon economy. And low carbon economy requires modern manufacturing logistics support.

Manufacturing enterprise logistics support the production and consumption of green logistics. Low-carbon economy is not only the contact the bridge with green manufacturing and green consumption, and the production of green logistics can be counterproductive to promote green manufacturing through distribution. And through green logistics management to meet and promote green consumption.

\section{Outstanding problems of manufacturing logistics system}

\section{Waste of transport resources}

In 2010, the "logistics cost analysis" shows transportation costs accounted for $58.9 \%$, storage costs is $2.9 \%$, and distribution and logistics processing costs accounted for $12.6 \%$ and $7.8 \%$, respectively. Transport links are the key to control of logistics costs. Unreasonable transport as unelaborated transportation route design, more transit times, too far transport, transportation repeated and so on. It not only increases the cost of logistics enterprises, but also it causes great waste of social resources. Meanwhile it increases the emissions of pollutants and environmental pollution problem [2]. Transportation links is the most important part in manufacturing enterprise logistics system. It includes the procurement of transport, distribution and transportation and sale of transportation, and mainly trains, trucks, ships and aircraft and other transportation mode. And it consume mainly petroleum products. Repeat transport and logistics industry, multiple transit transport the whole manufacturing logistics cause serious waste of resources.

\section{Warehousing poor infrastructure and high consumption of resources}

Manufacturing companies confront the prevalence of small and backward technology completely (material warehouse storage facilities, semi-finished and finished products warehouse and ancillary equipment) and other outstanding issues, resulting in high storage costs and resource consumption. Enterprises should construct warehouse storage infrastructure and take large-scale investment in general. They take up resources as land, building materials, steel and others. Choosing building, they not choose environmentally, energy-saving materials, resulting in a massive waste. Meanwhile, a serious shortage of information technology in warehouse management and information technology single service imperfectly have make warehousing operations still remain high error rates in the original, manual calculation stage in higher inventory costs.

\section{Waste packaging resources}

In the process of manufacturing logistics, the product of effective packaging is very necessary. It is the communication link between businesses and consumers.

However, because of cost considerations, enterprises are often poor quality of packaging materials or for the implementation of overprotection and excessive packaging, such as anomaly. Therefore, businesses continue to emphasize the "visual impact" or "eyeball economy." Moreover, the packaging material or utensils easily produce large amounts of waste, such as bags, boxes, bottles, cans, barrels, boxes, etc., and there are many of these waste materials are difficult to degrade, and even non-degradable. Moreover, the product of excessive packaging, expensive packaging, at the same time, waste of resources, but also generated a lot of packaging waste, which are to a large extent caused by the waste of resources and environmental pollution .

\section{Backward technology of logistics information management and lack of resource sharing}

Because of the logistics industry to deal with many industries, such as customs, civil aviation, railways, etc., public logistics information platform construction lag behind have make the logistics information scattered and the information unshared, leading information resource be integrated to 
form the "islands of information" ineffectively. Constructing logistics information, the vast majority of logistics enterprises lack management talent who both familiar logistics management services, understand computer technology, network technology and communication technology-related knowledge. Also they are familiar with the modus operandi of modern logistics information technology, high-level complex professional logistics information[3].Therefore, the promotion of organic integration of manufacturing and logistics industry is an important way to adjust the industrial structure and convert the mode of economic growth.

Development of low-carbon economy is to achieve the conservation of resources and strengthen environmental protection in the process of socio-economic activities. Logistics production and consumption contents of the structure of socio-economic activities. Development of low-carbon in manufacturing logistics, let alone the logistics industry, low-carbon economy has a pivotal role to achieve.

\section{Measures of low-carbon manufacturing logistics system}

\section{Create awareness of low-carbon economy}

Conserve resources and reduce environmental pollution must rely on each organization and individual's initiative to achieve. To achieve the development objectives of low-carbon economy, the first and most important factor is the importance of each individual "low carbon" understanding and treatment of "low carbon" scientific attitude.

For our multinational operations manufacturing sector, on the one hand, a low-carbon economy to strengthen awareness of employees through training and education so that employees understand the way of low-carbon economy. Low carbon economy attitude through wide publicity make sense of deep inner staff. They conduct for employees to perform through the development of staff daily low carbon standards. So that you can let employees in all aspects of research, production, operation, management and other low-carbon targets, so as to ensure that multinational enterprises in the lowcarbon economy and sustainable development.

On the other hand, government should strengthen consumer awareness of low-carbon, due to multinational enterprises facing consumers in different countries. While citizens of different countries have very different level of awareness for a low-carbon economy. Low carbon economy is relatively backward in consciousness countries and regions through changing the angle of product promotion. So that consumers accept the concept of low-carbon products from. Helping local people understand through propaganda and other activities obligation. Gradually it adapt to a lowcarbon economy low carbon lifestyle, especially for manufacturing industry awareness of lowcarbon economy.

When consumers' willingness to pay for low-carbon products and services increasing gradually, and they all will be through changes in consumer choice reflected. And consumer concerns of corporate reputation which focus on whether the enterprise in achieving low energy consumption, low emission, low pollution model of economic development on a leadership role, whether it made a great contribution in addressing climate change. Then it urgently requires companies to take practical measures to shoulder social responsibility [4].

\section{Low-carbon transport}

Designing the transportation routes of logistics, companies should strengthen the meticulous management of transport routes, try to arrange nearly produced and sold, choose direct mode of transport, reduce Intermediate links of transportation as transit transport, unloading and handling. Meanwhile, selecting transport routes, companies should strengthen remote management options of transport routes, not only to choose the best route, but also design alternatives of changing the route or offset to cope with the inevitable changes in the route or other conditions. In pollution transport, businesses can choose a new energy and renewable resources as a power fuel to reduce toxic gas emissions and environmental pollution[5]。

Storage facilities for low-carbon

During the construction of warehousing, manufacturing companies not only to plan warehousing 
facilities and overall layout logistics in scale rationally, to reduce duplication and to reduce the use of land resources, but also to construct the storage facilities using green building technologies, thus achieving the conservation of resources and reduce the purpose of environmental pollution. The use of bar code technology and EDI systems faith in storage facilities, in the current rates were $67.4 \%$ and $37.2 \%$. They still need to develop innovative information technology, logistics and construction. Enterprise competition is the talent competition, so talent is an important resource of the company. Companies need the skilled and management talent who use a variety of resources to improve the utilization of warehouse to build storage facilities.

\section{Integrated resource sharing and logistics system}

In response to the construction of a low-carbon economy, manufacturing logistics information management capacity should be strengthened, not only to improve the application of information technology, but also to accelerate the pace of information sharing. On the one hand, the manufacturing sector to strengthen the application of logistics information management and technology, building a sound and comprehensive logistics information database, besides strengthening the mutual convergence and integration of all aspects of database information. On the other hand, using advanced information technology, communications transmission technology, electronic sensor technology and other effective integration, companies establish intelligent transportation management system. In 2009, Chinese networking industry market reached 171.6 billion yuan, which is expected to 2015, networking overall market will reach 750 billion yuan, the annual compound growth rate of over $30 \%$. The market outlook will be much more than computer, the Internet, mobile communications market and so on.

On the one hand, the manufacturing enterprises should strengthen the application of logistics information management and technology. Building a comprehensive logistics information database (included transportation, warehousing, distribution, circulation, processing, handling, packaging information database of all aspects of the building). Meanwhile enterprises also strengthen various aspects of mutual convergence and integration of information in the database.

On the other hand, the manufacturing enterprises establish intelligent transportation management systems using advanced information technology, communications transmission technology, electronic sensor technology, electronic control technology and computer processing technology, effective integration. Such as the development and application of GPS vehicle tracking and positioning systems, GIS systems, vehicle wiring arrangement technology and use of the existing internal network systems and e-commerce systems unified national freight network, build a national and even international networking systems, receive and provide national the sources of information. This will not only be able to realize the sharing of resources, and it can reduce the waste of resources and environmental pollution which coursed the convective transport, transportation and repeat roundabout brings irrational modes of transport and transport effectively [6].

\section{Manufacturing logistics system management efficiency}

In traditional manufacturing enterprise logistics systems (such as procurement, transportation, storage, marketing and other activities), although they subject to the corporate executives, they are only responsible for a part of the logistics of personal work. And they failed to form a corresponding system. It does not conducive to logistics performance improvement. The organization is composed of modern logistics enterprise logistics input, internal circulation, the output. And it forms the core of the logistics system.

Thus, management organization for recycling for the manufacturing enterprise logistics is necessary [7]. Manufacturing enterprises can improve the efficiency of the organization through recycling logistics system management organization. And manufacturing enterprises achieve organizational streamlining by personnel selection training. They encourage enterprises to move in the direction of low-carbon development [8-9].

\section{Summary}

Planning manufacturing logistics system is a complex social system, its construction is not easy, especially in the current era of low-carbon economy. Manufacturing logistics system of China in 
imperfect operating, only to upgrade the traditional outdated technology, but also to develop and improve the application of low-carbon technologies in the logistics system.

Therefore, in order to achieve low-carbon economy purpose---high efficiency, low consumption and green, and required to comply with China conditions to bring about sustainable development of human, manufacturing companies not only to consider their own logistics efficiency, but also to establish a recycling system in the entire logistics.

\section{References}

[1] Liu Wei-Hua, Manufacturing Logistics 2010 Prospect and 2011 Review. Special Report,2, pp.70-71, 2011

[2] Wei Wen-Xuan, Enterprise Logistics System redesign basing on a low-carbon economy. Logistics,10,pp.25-26, 2010

[3] Bai Chen-Xing, modern Logistics Information Problems and Countermeasures in China. Reformation \& Strategy 6,pp. 156-158, 2010

[4] Wang Xiao-Yan, Chinese multinational enterprises develop new ideas for the next model of a low-carbon economy. Special Zone Economy, 5, pp.232-233,2010

[5] Gao Hong-Ye, Optimization of Manufacturing Logistics System. Management Research,6, pp.12-13,2012

[6] Peng Guang-Hui, Manufacturing Enterprise Logistics System problems and countermeasures. Perspective,7,pp.30-33,2010

[7] Dai Hong-Mei, Theoretical Reflection on the development of low-carbon economy. Enterprise economy, 8,pp.58-60,2011

[8] Duan Xiang-Yun, The impact and operating mechanism of low-carbon development mechanism of logistics enterprises. Tianjin University of Finance and Economics, 2011

[9] Wu Fan, Remanufacturing Assessment and Logistics System Model, Dalian University of Technology, 2012 